\title{
Os processos formativos da corporeidade e o marxismo: aproximações pela problemática do trabalho
}

\author{
Carlos Herold Junior
}

Universidade Estadual do Centro-Oeste, Departamento de Pedagogia.

\section{Introdução}

Um dos limites mais apontados por críticos ao materialismo histórico é a pretendida incapacidade desse referencial em lidar com questões ligadas aos estudos sobre o corpo. Por sua vez, também é comum o fato de analistas marxistas imputarem a essa temática um caráter de "modismo", um desvio das questões que, efetivamente, seriam mais importantes ou "estruturais".

Este estudo objetiva problematizar essas duas assunções. Pretendemos evidenciar que os estudos sobre a corporeidade e sua formação, apesar de terem seu surgimento e fortalecimento no seio do paradigma pós-moderno, podem ter seus questionamentos aprofundados se tiverem por base diretrizes metodológicas que se sustentam no materialismo histórico. Além disso, queremos mostrar que os estudos da corporeidade podem constituir-se em esforços valiosos para o aprofundamento das críticas encetadas a partir do materialismo histórico, configurando-se, para ele, em um desdobramento necessário a ser empreendido para o enriquecimento de suas análises.

O ponto sobre o qual se apóia tanto a distância quanto a almejada aproximação entre os estudos do corpo e as análises de Marx é o conjunto de limites e o papel que atribuem ao trabalho, respectivamente. $\mathrm{O}$ estudo da relação entre corpo e trabalho e a amplificação de seus resultados surgem como possibilidades de considerarmos a formação da corporeidade humana pelo prisma do materialismo histórico. Sendo fácil encontrar pesquisadores, professores e interessados em geral em discutir a corporeidade, de um lado, e em discutir o mundo do trabalho, de outro, é extremamente difícil encontrar estudos que versem sobre a corporeidade e suas relações com esse mundo. Mcnally (2001) nota que um dos pontos mais comuns em suportes analíticos pós-modernistas é acreditar no "fim do trabalho", no "fim da história" e no "fim na economia política do corpo". ${ }^{1}$ Eagleton (1998) afir-

${ }^{1}$ Baudrillard (1999), por exemplo, diz: "O que será do Outro quando ele desaparecer? O que se torna o Real, o que se torna o corpo quando eles foram substituídos pela sua fórmula operacional? O que se torna o sexo, o trabalho, o tempo e todas as outras figuras da alteridade, quando elas caem sob o golpe da síntese tecnológica?” (p. 57). Mais à frente, ele responde: “Assim, a arte, o trabalho a religião e o corpo esqueceram de morrer" (p. 60). 
ma: "Se o corpo libidinoso está in, o corpo laborioso está out” (p. 74). Lee (1999) também chama atenção para o mesmo fato: "talvez um dos mais desconcertantes aspectos dessa obsessão com o corpo é a não atenção ao corpo no trabalho" (p. 208). Esse limite, passível de ser explicado, é ao mesmo tempo a causa e a conseqüência para que os estudos da corporeidade e do materialismo histórico sejam vistos e se vejam como antípodas.

Para colaborar com a superação dessa dificuldade, elaboramos uma reflexão dividida em três momentos: no primeiro, elucidamos como a temática da corporeidade aparece na atualidade vinculada ao desenvolvimento do pós-modernismo; no segundo, evidenciamos que há, em relação a Marx, um debate em torno das suas possibilidades para o estudo das questões do corpo e as do trabalho; por fim, exploramos algumas pistas analíticas oferecidas por Marx que, ao colocar o trabalho humano como ponto de partida e chegada das análises, possibilita que as discussões sobre a formação da corporeidade e de seus desdobramentos encontrem condições para que suas constatações tenham seus resultados positivos maximizados.

\section{A questão do corpo e os vínculos com o referencial pós-modernista}

O corpo, seu cuidado, seu tratamento e sua educação, hoje, são alvos de uma quantidade imensa de estudos e preocupações. Discute-se o corpo cotidiana e freqüentemente nos meios de comunicação, nas conversas informais; pensa-se publicamente sobre a corporeidade, depositando nela uma preocupação que pretende remediar um "esquecimento" e, com isso, construir uma vida com mais prazer e significado. ${ }^{2}$

Essa temática, conseqüentemente, é uma presença certa nas discussões acadêmicas, podendo ser observadas, nas mais diferentes áreas do conhecimento, análises que enfatizam seu significado. Em contra-

\footnotetext{
${ }^{2}$ Ver Juvin (2005), bem como Le Breton (2003).
}

partida, concordamos com Eagleton (1993), quando ele afirma: "sinto-me pouco à vontade em relação ao modismo do tema: poucos textos hoje em dia serão aceitos dentro do novo cânone historicista se não contiverem pelo menos um corpo mutilado" (p. 11).

As discussões acadêmicas sobre o corpo ensejam um conjunto de preocupações e "inovações" metodológicas que se coadunam com a ambição de se preocupar com o específico, com a imagem, com o discurso, com as idiossincrasias. Com isso, elas assumem a impossibilidade de elaborarmos uma análise que ambicione entender a temática com o intuito de uma compreensão e de uma crítica que contemple questões mais gerais. Afirma Mcnally: "a conversa do corpo está em todo lugar no discurso pós-modernista" (2001, p. 2). O crítico literário inglês constata que, "como fenômeno obstinadamente local, o corpo combina muito bem com a desconfiança pós-moderna em relação às grandes narrativas, assim como a paixão do pragmatismo pelo concreto" (Eagleton, 1998, p. 73).

Apesar do desconforto que um estudo sobre a corporeidade pode causar em virtude do íntimo relacionamento com análises de caráter "pós-classista que se escondem na intensidade do corpo para fugir a questões exageradamente 'globais"” (Eagleton, 1993, p. 11), há que se fazer o esforço para guiar a reflexão para as questões concernentes aos processos mais ampliados de transformação social. Harvey (2000), por exemplo, focaliza a questão do corpo na sociedade atual para completar a análise que faz sobre a questão da globalização. Para o autor, falar de corpo depois de falar de globalização é uma tentativa de explicar "especificamente", "localizadamente", um fenômeno de escala planetária. Ao mesmo tempo, ele faz uma importante advertência sobre o crescimento dos estudos sobre o corpo:

Logo, embora se possa justificar o retorno ao corpo, entendido como a sede de um fundamento (epistemológico e ontológico) mais autêntico das abstrações teóricas que têm dominado por tempo demasiado como puras abstrações, ele não pode, em si e por si, garantir nada além da produção de uma auto-referencialidade narcisista. (p. 140) 
Todavia, tão limitante quanto reduzir a busca da compreensão sobre a corporeidade a uma dimensão cultural "localizada", seria negar que essas análises apresentam questões importantes e que devem ser consideradas. Verificamos que é justamente esse malestar, essa suspeita e esse reconhecimento que evidencia a necessidade de analisar esse objeto mais detidamente, tanto no âmbito específico quanto no âmbito geral. Aliás, é esse cuidado que possibilita assumirmos que a "retomada do corpo foi uma das mudanças mais importantes no pensamento radical recente", com a qual pretendemos colaborar ao fortalecer a "extensão desta fértil tendência de investigação numa nova direção" (Eagleton, 1993, p. 11). Essa assunção, por sua vez, não deve obscurecer o fato, sublinhado por Foster (1999), de que "as fraquezas do pós-modernismo ${ }^{3}$ - vistas de uma perspectiva emancipadora - superam de longe, portanto, seus pontos fortes" (p. 203). Wood (1999), ao falar sobre as preferências temáticas do pós-modernismo, tais como as "outras 'identidades' além da de classe", a repressão sexual, a discriminação racial, o meio ambiente e, por que não, a corporeidade, ${ }^{4}$ afirma que "nenhum de nós pretende negar a importância de alguns temas pós-modernistas" (p. 17).

${ }^{3}$ Para ilustrar como as positividades e críticas geradas pelos matizes pós-modernistas perdem força pelas contradições e limites dessa tendência, Gil (1997) observa em relação à preocupação com o corpo: "Assiste-se actualmente, depois do esforço psicanalítico, a uma verdadeira invasão do culto ao corpo [...] Muito estranhamente, na mesma altura em que esta voga testemunha uma sensibilização crescente pelos problemas do corpo tendente a afirmar sua importância nos mais diversos domínios, retomam-se velhas idéias, velhos esquemas - idênticos aos regimes de signos que serviram para a exploração do corpo: este se tornou o significante despótico que resolverá tudo, desde o declínio da cultura ocidental, até aos menores conflitos intra-individuais" (p. 14).

${ }^{4}$ Villaça e Góes (1998) apresentam de forma resumida a configuração dos estudos sobre a corporeidade no interior do pósmodernismo: "Os teóricos contemporâneos se empenham em caminhos variados que optam pelos hinos aos avatares naturalistas,
Essas afirmações são importantes desde que levemos em conta o cuidado com que Jameson (2002) analisa o pós-modernismo, entendido pelo autor como um movimento do capitalismo tardio. Ele adverte que, ao falarmos em pós-modernismo, devemos considerar que se trata de um conjunto de concepções estéticas, políticas e filosóficas que não aceita facilmente qualquer tipo de classificação e ou definição.

No caso específico da corporeidade, no esteio do mesmo referencial que a valoriza, há também analistas que enxergam o corpo como algo superado por ser limitado ante a inteligência. Isso é criticamente observado por Mcnally (2001), quando pondera que a importância que se vem dando ao corpo é um meio de negar a sua materialidade, encarando-o como "discursivo". Para o autor, essa é a forma mais presente de um novo idealismo cujo discurso pós-modernista é o grande exemplo. Mooers (s.d.) observa que: "Transformando o corpo em uma abstração discursiva o pós-modernismo meramente retoma o dualismo mente/corpo dos tempos anteriores" (p. 22).

Esse autor também nota que algumas correntes filosóficas baseadas nas tendências pós-modernistas enxergam a "descorporificação" como um sinônimo de emancipação. Afinal, "liberados dos constrangimentos da corporeidade, pode ser pensado que nós poderíamos também ser liberados de várias formas de discriminação corporal expressas no racismo e sexismo" (p. 17).

Buscando evitar que questões importantes trazidas pelos debates filosóficos nas últimas décadas se-

por versões neo-iluministas de controle, por movimento libertários do corpo, seja como organismo (linha nietzchiana), seja como campo de forças (Deleuze). Opções pelo corpo hedonista e narcísico no contexto da cultura do consumo (Lipovetsky), delação das estratégias de controle nas suas mais diversas formas com propostas de micropolíticas defensivas (Foucault), reflexões sobre o corpo do consumo de viés neomarxista (Featherstone, Canclini), versões das novas apropriações do corpo alienado no consumo (Eagleton) ou tiradas apocalípticas sobre o fim da corporeidade na simulação total (Baudrillard)” (p. 42). 
jam simplesmente negligenciadas ou desvalorizadas ${ }^{5}$ (a questão do corpo é uma delas), assumimos como importante a discussão da corporeidade (o que vai ao encontro do que se denomina "concepções pós-modernas"), mas buscamos focalizar a problemática do corpo tendo por objetivo relacioná-la com as análises feitas por Marx e sua preocupação em tematizar as transformações políticas, sociais e econômicas mais amplas, esforços analíticos estes criticados pelas correntes de análises sobre o corpo: tanto por aqueles que o glorificam quanto por aqueles que o concebem como ultrapassado.

\section{Marx e as análises da relação corpo e trabalho: alvo de crítica ou ponto de apoio}

Verificamos que, quando a questão é o corpo no e pelo trabalho, há a consideração do pensador alemão, ora favoravelmente, ora contrariamente. O debate em relação às correntes formas de análise do corpo feitas pelo ou contra o ideário pós-modernista, vistas pelo ângulo do trabalho, implica um posicionamento perante as análises do trabalho feitas por Marx (1994).

Para Dale (2001), Marx foi um dos primeiros a abordar a forma como as organizações e a divisão do trabalho afetam o corpo. Ela afirma que "reconhecendo Marx o problema do corpo, seu trabalho focaliza a organização social que o produziu" (p. 125). A autora continua a ocupar-se de Marx, mas agora verificando o limite das idéias do autor de $O$ capital especialmente com relação às críticas que ele faz da mercantilização do trabalhador. Essa própria crítica seria refém de um certo dualismo: "ao invés de desafiar o dualismo sujeito/objeto, ele tende a se mover

\footnotetext{
${ }^{5}$ Sobre isso, afirma Leandro Konder (1998): “Complexo e contraditório como é, o pós-modernismo não só expressa a realidade social fragmentada do presente, legitimando-a, mas também corporifica, em inúmeros aspectos, uma atitude de insatisfação, de rebeldia implícita em face dela, trazendo algumas observações agudas que nos ajudam a compreendê-la" (s.p.).
}

da desvalorização do objeto para tentar reafirmar a superioridade do sujeito, deixando assunções subliminares intocadas" (p. 193).

Para Böhle e Milkau (1998), a própria idéia de trabalho passa a ser considerada inadequada, sobretudo quando é assumido o conceito de que trabalho é uma atividade racional para atingir um fim. Para evidenciar sua crítica, os autores tomam Marx como exemplo, quando ele explica a diferença entre o trabalho do homem e o das abelhas. Isso, entre outras coisas, dizem os autores, redundaria na própria divisão entre trabalho intelectual e trabalho manual ou físico. Na mesma trilha, Hancock e Tyler (2002) chegam a afirmar que o marxismo é um exemplo de pensamento que acreditava ser crítico sem contemplar a corporeidade.

Apesar das críticas recebidas, o referencial marxista é freqüentemente utilizado para problematizar tanto o relacionamento entre corpo e trabalho, como a própria produção sociológica e antropológica sobre o corpo. Le Breton (2002), ao fazer uma análise dos estudos em sociologia que se preocupam com as representações sociais da corporeidade, configurando uma sociologia do corpo, observa que as obras de Marx e Engels têm lugar importante. Mesmo sem terem intencionado estudar o corpo diretamente, suas análises sobre o mundo do trabalho proporcionam a base para estudos posteriores que se focalizaram sobre a questão do corpo no interior da sociedade.

Shilling (2005) afirma que um dos méritos da obra de Marx é a busca de uma análise em que o relacionamento entre a natureza e a sociedade é levado em conta de forma complexa. E isso, diz Shilling (2005, p. 40), passa por toda obra de Marx, indo dos Manuscritos até $O$ capital.

Scarry (1985), diferentemente do que afirma Hancock e Tyler (2002), nota que Marx, em toda sua obra, "assume que o mundo feito é o corpo do ser humano e que, tendo projetado o corpo ao fazer o mundo, homens e mulheres são descorporificados, espiritualizados" (p. 244). Além disso, quando o filósofo alemão trata da terra ou de qualquer artefato tecnológico, ele os define como um prolongamento do 
corpo do trabalhador. Entretanto, há diferenças entre os vários momentos em que Marx fala da técnica ou da produção e seus meios como prolongamentos corporais $^{6}$ do trabalho, refletindo, assim, o próprio desenvolvimento de seu pensamento:

A discrepância entre o tom dos escritos de Marx quando ele reconhece a presença do corpo em lugares elementares do artifício (matérias-primas, ferramentas, objeto material) e o tom de seus escritos quando ele reconhece sua presença em lugares mais sofisticados (dinheiro, capital fixo, capital circulante, capital produtivo [...]) surge não apenas do fato que sua ocorrência é muito mais literal no primeiro caso, mas também porque sua ocorrência é muito menos estipulada, politicamente. (p. 249)

Harvey (2000) verifica que a base de uma "concepção relacional" do corpo é possível de ser verificada na obra de Karl Marx. ${ }^{7} \mathrm{O}$ autor americano afirma que o corpo pode ser entendido e discutido se for também estudado pelo materialismo histórico de Marx. Afinal,

Como todos vivemos no mundo da acumulação e da circulação do capital, essa teoria tem de ser parte de toda discussão sobre a natureza do corpo contemporâneo. Evitar isso (com base na especiosa alegação de que as categorias de Marx estão desestabilizadas ou, pior ainda, desatualizadas ou ultrapassadas) é desprezar um aspecto vital de como o corpo tem que ser problematizado. (p. 141)

${ }^{6}$ Sobre a relação entre técnica e corporeidade, a obra de Ernst Kapp (1877), sobretudo o capítulo "Die Organprojection", merece ser considerada. Para um estudo sobre a obra de Kapp, ver Leinenbach (1990).

${ }^{7} \mathrm{O}$ autor enfatiza, porém, que isso não quer dizer que a obra de Marx tenha desenvolvido todas as possibilidades para a análise da corporeidade. Ausências sobre questões sexuais, de gênero e raça, entre outras, por sua vez, não inviabilizam a obra de Marx como uma das bases para o estudo da corporeidade em suas vinculações sociais.
Rabinbach (1992) chama atenção para a relevância de Marx para o entendimento não só das questões do trabalho mas para as questões do relacionamento entre corpo e trabalho. Esse processo de transformação das características do trabalho tem conseqüências que Rabinbach (1992) menciona já no início de sua obra como resultados metodológicos decorrentes das transformações produtivas. Uma das conseqüências possíveis de serem vistas nesse processo é o fato de muitos teóricos terem abandonado o marxismo, tido como a filosofia "produtivista" por excelência. Com isso, não mais o trabalho, mas a família, a linguagem, a sexualidade etc. começariam a merecer uma atenção que não recebiam. $\mathrm{O}$ autor, porém, sem desconsiderar o fato, adverte:

Tendo abandonado o Marxismo, muitos historiadores sociais tornaram-se suspeitos da teoria e dispensaram seu próprio produtivismo anterior como um erro metodológico. A correção do erro, entretanto, freqüentemente desvia-se totalmente da análise do problema: nesse caso, a desconsideração das assunções produtivistas do Marxismo como uma força histórica merece uma investigação crítica. (p. 15)

Notando que essas conclusões sobre o trabalho e sobre o corpo influenciam e são influenciadas pelo desenvolvimento do debate científico, sociológico e filosófico, Rabinbach (1992) relaciona a mudança do corpo visto como "motor" para o corpo visto como "informação", com a suposta superação da perspectiva dita "produtivista" de Marx. Isso em favor de abordagens que acentuam de forma mais intensa as dimensões comunicativas e ideológicas do trabalho. Rabinbach, porém, também pondera:

[...] afirmar que a realidade material da "sociedade do tra-
balho" foi suplantada pela "sociedade da informação" - ou
"da imagem" - é, entretanto, ignorar a dimensão ideológi-
ca e cultural do "materialismo" e a centralidade do corpo
no pensamento do século XIX. (p. 299)

Podemos ver que todas essas advertências endossam que hoje a questão do trabalho é fundamental 
e que, da mesma forma, o referencial marxista apresenta possibilidades que aqueles que se apegam às manifestações as mais superficiais dos estudos sobre a corporeidade não conseguem entender. Entre elas, a necessidade de abordar o corpo tendo como anteparo o mundo do trabalho e, ao mesmo tempo, enxergar o trabalho pelas questões do corpo.

\section{Possibilidades para a consideração da formação da corporeidade por meio das análises de Marx}

A necessidade de considerar as dimensões produção e consumo nos estudos sobre o corpo

Marx (1994) analisa que o ponto central da exploração capitalista se dá no consumo da força de trabalho, uma mercadoria "especial" que possui a capacidade de produzir valor. A dialética entre trabalho concreto e trabalho abstrato, seguida por Marx na construção histórica da classe trabalhadora como vendedora de sua "pele", é a base para explicar o fato de uma exploração dar-se com a aparência de uma relação juridicamente equânime. Ao comprar a capacidade de trabalho, abstratamente considerada, e consumi-la concretamente, o proprietário dos meios de produção extrai a mais-valia, dando início a um ciclo mediado pelas dimensões culturais, políticas, científicas e tecnológicas, que se determinam mutuamente nesse "momento" de troca e produção, de consumo e trabalho, de produção coletiva e apropriação privada, pela contradição entre a necessária organização da fábrica e o caos da divisão social do trabalho. Indo além, ao atribuir ao trabalho o centro do processo de construção, compreensão e superação do capital, Marx o faz dando atenção tanto ao "processo de trabalho" quanto ao amplo processo de divisão social do trabalho. Não é somente o trabalho, atividade, que conta, mas sim o trabalho no sentido amplo, que compõe, por sua vez, a categoria modo de produção, que engloba, além do processo de trabalho, a divisão social do trabalho e suas mediações jurídicas, políticas e culturais. Nesse raciocínio, não é possível atribuir prioridade ao consumo, à circulação perante a produção. O modo de produção capitalista é a totalidade das relações sociais, estabelecidas para a produção social.

Essa advertência é necessária, pois os limites com os quais o trabalho é analisado levam os teóricos a decretar a irrelevância da produção para o entendimento da sociedade, vendo no consumo o único ponto de apoio para as análises. Para tornar a situação ainda mais desvantajosa para o estudo do mundo do trabalho, Lessa (2005) observa que se passa a afirmar que é o consumo que determina a produção ou que o consumo se torna produção, tal como fazem Negri e Hardt (2000).

A complexidade desse relacionamento entre produção e consumo já é verificável no início do século XX. Na realidade, é uma reação em sentido oposto ao que era observado na esfera do consumo. Seltzer (1992) nota que, nas últimas décadas do século XIX e nas primeiras do século XX, paralelamente ao processo de racionalização, de mecanização do corpo no processo produtivo, há um retorno do corpo, um elogio a suas capacidades sensíveis, contrariamente ao que era feito no meio produtivo. Veblen (1899) chama esse retorno de archaic traits da natureza, uma reação à substituição do corpo pelas máquinas. Seltzer (1992) sublinha que esse apelo para um resíduo da "natureza humana" hoje é altamente aceito, sendo inclusive adjetivado de "familiar" (p. 62) pelo autor. Vale a pena registrar que, para Veblen (1899), vivendo e escrevendo no momento em que as representações do corpo eram baseadas no trabalho industrial, o mundo do consumo era considerado compensação, fonte de fruição, o que contrastava com a penúria "fisiológica" do trabalho. O consumo era visto, então, como a possibilidade do prazer que as exigências físicas do trabalho não proporcionavam. Arendt (2005) nota que havia a tendência de rebaixar as atividades de trabalho e compará-las às atividades "livres", desenvolvidas ou praticadas no momento de lazer. Em contrapartida, e ao mesmo tempo, são justamente esses desenvolvimentos do mundo do trabalho que possibilitaram o surgimento da sociedade de massa, que 
ocasionou influências diretas sobre a maneira de "apropriação" do tempo de não-trabalho pelo trabalhador... no momento de consumo. Como resultado,

[...] seu profundo mal-estar é uma infelicidade causada de um lado pela falta de equilíbrio entre o trabalho e o consumo, de outro pelas exigências obstinadas do animal laborans que quer uma felicidade que só obtemos no equilíbrio perfeito dos processos vitais de esgotamento e geração, de sofrimento e alívio. (Arendt, 2005, p. 184-185)

$\mathrm{Na}$ atualidade, todavia, ocorre um fenômeno diverso. Com a crescente incorporação tecnológica e a superação da figura do human motor como metáfora do corpo que trabalha (Rabinbach, 1992), o consumo deixa de ser visto como compensação, como meio da manifestação da "sobrevivência do arcaico". O consumo passa a ser concebido como a única esfera em que o corpo é "produzido" e "reproduzido", ao mesmo tempo em que o corpo se torna um dos principais objetos de consumo e o grande causador de consumo.

Um dos pontos que sustentam a possibilidade de superar limites e proporcionar condições para o aprofundamento da questão do corpo e do trabalho é uma consideração mais detida sobre o relacionamento entre as esferas do consumo e da produção, justificada pela forma como o mundo do consumo passa a ser visto como "o" locus para o estudo do corpo, em detrimento das questões concernentes ao trabalho. Não que essas análises não tenham apresentado observações relevantes sobre a questão do corpo. Esses resultados, porém, poderiam ampliar suas conseqüências se tivessem partido de outras premissas. Baudrillard (2005), por exemplo, ao definir o que ele chama de sociedade do consumo, relaciona suas reflexões sobre a importância do consumo defendendo que o corpo assume no interior do processo importância central:

Na panóplia do consumo, ele é um objeto o mais bonito, mais precioso, mais vibrante que todos $-[\ldots]$ é o corpo. Sua redescoberta, depois de uma era milenar de puritanismo, sob o sinal da liberação física e sexual [...] na publi- cidade, na moda, na cultura de massa [...] tudo testemunha que o corpo, hoje, tornou-se um objeto de redenção. (p. 200)

Baudrillard (2005) quer mostrar que a "liberação" do corpo e a busca dos seus prazeres significam uma exploração tão radical tanto quanto aquela que "ocorria" quando o corpo era "apenas" força de trabalho. As manifestações dessa "nova prisão" são as buscas frenéticas pela beleza e pelo erotismo. Ele não nega que as "novas" configurações do trabalho sejam elas também fonte de fadiga, entendida na acepção de "gasto energético" manifestado na ausência de movimento, nas longas horas na mesma posição, nos pequenos gestos repetidos até a exaustão e nas lesões que isso acarreta. Entretanto, diz Baudrillard:

\footnotetext{
[...] isso não é o essencial, [...] porque nós não curaremos a fadiga patológica pelo esporte e pelo exercício muscular, como nos dizem os especialistas ingênuos (não mais que por tranqüilizantes e estimulantes). Pois a fadiga é uma contestação latente, que se dirige contra si mesmo e se encarna no seu próprio corpo porque, em certas condições, é a única coisa à qual o indivíduo despossuído pode se agarrar. (p. 293-294)
}

O prisma levantado pelo filósofo francês é relevante, considerando a forma como o seu pensamento é aceito e difundido nos estudos sobre o corpo e o trabalho. Dale (2001), por exemplo, verifica que, mesmo estando presente, tanto na ciência quanto na administração, e sempre ter sido uma mercadoria sujeita a todas as determinações da base econômica da sociedade, hoje, o corpo assume um relacionamento mais próximo com a definição de estilos de vida e de subjetividades e que, por isso mesmo, se tem tornado um alvo ainda mais requisitado pelas estratégias do consumo, passando a ser visto em sua capacidade de consumir: "Talvez, na sociedade moderna, produção e consumo se fundiram em um só, via economia do corpo" (p. 45).

Lowe (1995) apresenta como uma das balizas de suas análises as body practices. Por body practices ele entende o processo de produção e satisfação de 
necessidades corporais, mediadas ou não pela sociedade. $\mathrm{O}$ que o autor nota em relação ao capitalismo tardio, sobretudo o norte-americano, é que se assiste a um processo intenso de mercantilização e exploração das body practices que até então não eram alcançadas em sua privacidade pelo capitalismo industrial. Sibilia (2002) expressa assim a idéia de primazia do consumo sobre a produção:

Não se trata mais, portanto, daqueles corpos laboriosamente convertidos em força de trabalho, esculpidos em longas e penosas sessões de treinamento e disciplina para saciar as demandas da produção industrial; [...] agora emergem outros tipos de corpos e outros tipos de subjetividade: autocontrolados, inspirados no modelo empresarial, imbuídos a administrarem seus riscos e seus prazeres de acordo com o seu próprio capital genético, avaliando constantemente o menu de produtos e serviços oferecidos no mercado. (p. 207)

Hetrick e Boje (1992), contrariamente, afirmam que espaços de resistência e análise podem ser obtidos e construídos tanto na esfera produtiva quanto na esfera do consumo, sendo possível verificar como trabalhadores e consumidores são constituídos levando em conta as mudanças a que assistimos com o surgimento da "era pós-moderna".

Mesmo com a possibilidade de analisar as mudanças nas duas esferas, as questões do corpo no âmbito do consumo tornam-se aparentemente mais importantes. Porém, o controle do corpo que acontece na esfera do consumo, na atualidade, fora inventado e posto em prática pela produção capitalista. Esse fenômeno, que acontece desde os inícios do taylorismo e continua a ter lugar mesmo hoje, independe das novas denominações e manifestações com que acontece: "as necessidades do consumidor e do trabalhador são duas modalidades da mesma exploração das forças produtivas. $\mathrm{O}$ consumidor saturado aparece como a manifestação fascinada do assalariado" (Hetrick \& Boje, 1992, p. 55). Como resultado, Alves (2005) nota que no interior das atuais práticas de reestruturação produtiva, vistas como libertadoras das necessidades da exploração do trabalho do corpo, ocorre de fato uma "compressão psicocorporal": "Na verdade, o corpo não se emancipa da disciplina do capital, mas constitui-se uma nova relação psicocorporal que busca preservar um componente essencial das sociedades do capital, sejam elas modernas, ou pós-modernas: um corpo útil, produtivo ou submisso" (p. 422).

Há necessidade de tomar o relacionamento entre produção e consumo de forma aprofundada. Quando Lukács $(1979,2004)$ fala de um predomínio da produção, isso não quer dizer que o consumo é apenas um resultado, um fator secundário. Assumimos o fato de o consumo influir no mundo produtivo. Porém, no capitalismo a produção de mais-valia realiza-se no processo social de consumo, tendo por base a distinção entre trabalho produtivo e trabalho improdutivo proposta por Marx, ao buscar entender a produção dessa mais-valia.

O trabalhador não se vê como capital variável, mas busca cotidianamente produzir a si mesmo pelo seu trabalho. Para isso, entretanto, é necessário que o consumo seja "racional". Constatado isso, Harvey (2000) apresenta uma maneira de ver o corpo pelo trabalho conectado intimamente com o corpo no consumo sem ver neste somente o centro a ser buscado pelos analistas do corpo:

A organização, a mobilização e a canalização dos desejos humanos, o envolvimento político ativo com táticas de persuasão, vigilância e coerção tornam-se parte do aparato de consumo do capitalista, produzindo por sua vez todo tipo de pressões sobre o corpo como sede do "consumo racional", bem como seu agente performativo, para fins de maior acumulação. (p. 153)

Nesse relacionamento entre consumo e produção, o corpo do trabalhador, em toda sua especificidade e particularidade, fica exposto às forças que tocam a generalidade do modo de produção. É por isso que Harvey (2000) afirma que "o corpo que trabalha tem de ser visto como uma relação interna dos processos histórica e geograficamente concretizados de 
circulação do capital” (p. 157). Esse entendimento aproxima as preocupações relativas ao corpo que trabalha com as questões mais gerais sobre a corporeidade que os analistas procuram estudar:

O capital se empenha continuamente em moldar os corpos de acordo com seus próprios requisitos, ao mesmo tempo que internaliza em seu modus operandi efeitos de desejos corporais, vontades, necessidades e relações sociais em mudança e interminavelmente inacabados [...] da parte do trabalhador. Esse processo molda muitas facetas da vida social, como "opções" em termos de sexualidade e de reprodução biológica ou de cultura e modos de vida, ainda que essas "opções" [...] sejam plasmadas de modo mais geral pela ordem social e por seus códigos legais, sociais e políticos, bem como por suas práticas disciplinares. (Harvey, 2000, p. 157)

A desconsideração do corpo que trabalha, tanto pelos estudiosos do trabalho como pelos estudiosos do corpo, faz com que as possibilidades políticas da corporeidade e sua educação sejam rejeitadas. É isso que representam as idéias de superação do corpo e as concepções de que o corpo só é tematizável de forma verdadeiramente humana quando o que está em jogo são os prazeres proporcionados. Harvey (2000) afirma que "há necessidade de alguma outra coisa que permita a tradução do reino do corpo como 'carne' para a acumulação do capital ao conceito do trabalhador como agente político" (p. 162). Caso não seja feita essa análise da corporeidade laborativa como ponto de apoio para a luta política, o preço a ser pago é o fato de as análises do corpo endossarem reducionismos. O que se quer não é isso, mas sim o fato de que:

[...] o estudo do corpo tem que se basear na compreensão das relações espaço-temporais concretas entre práticas materiais, representações, imaginários, instituições, relações sociais e estruturas vigentes de poder político-econômico. Pode-se então ver o corpo como um nexo por meio do qual abordar possibilidades de uma política emancipadora. (p. 178)

\section{A dupla dimensão do trabalho: os processos históricos de formação da corporeidade e sua subsunção ao capitalismo}

Um avanço que Marx coloca para a história da filosofia é a assunção do duplo caráter do trabalho: seu caráter objetivador, construtor social do homem e, ao mesmo tempo, seu caráter subsumido às necessidades históricas dos diferentes modos de produção que, no caso do capitalismo, vem como fonte de mais-valia e, conseqüentemente, embrutecimento e exploração do trabalho. $O$ capital é um exemplo de obra em que essa dupla dimensão do trabalho está presente. Marx (1994) verifica que "a produção de valores-de-uso não muda sua natureza geral por ser levada a cabo em benefício do capitalista ou estar sob seu controle. Por isso, temos inicialmente de considerar o processo à parte de qualquer estrutura social determinada" (p. 201).

O trabalho, ao ser tomado em sua dimensão histórica específica e como relação entre homem-natureza que acontece em toda história, possibilita uma das chaves para o entendimento dos elos e das descontinuidades entre indivíduo e sociedade, entre privado e público, entre razão e sensibilidade etc. Para ilustrar essa possibilidade, Marx defende que a relação entre homem-natureza só se dá mediada pela sociedade, ao mesmo tempo em que a funda. O pensador alemão começa afirmando que:

\section{[...] o processo de trabalho é puramente individual, um úni- co trabalhador exerce todas as funções que mais tarde se dissociam. Ao apropriar-se individualmente de objetos na- turais para prover sua vida, é ele quem controla a si mes- mo; mais tarde, ficará sob controle de outrem. O homem isolado não pode atuar sobre a natureza, sem pôr em ação seus músculos sob o controle do seu cérebro. Fisiologica- mente, cabeça e mãos são partes de um sistema; do mesmo modo, o processo de trabalho conjuga o trabalho do cére- bro e o das mãos. $(1994, \text { p. } 584)^{8}$}

${ }^{8}$ A consideração dessas passagens de $O$ capital (1994) foi possibilitada pela análise que Lessa (2005, p. 55-57) desenvolve sobre os limites do pensamento de Negri e Hardt (2000). 
Com essa afirmação, Marx (1994) demonstra um entendimento sobre o corpo no trabalho em que a atividade concreta de produção da existência, comum em todas as sociedades, só acontece com a concorrência social de todas as capacidades humanas. Nesse sentido, Vasquez (1990), retomando esse encaminhamento, oferece uma importante consideração ao afirmar que:

[...] quaisquer que sejam os instrumentos de que se valha para transformar a matéria conforme suas finalidades, é, sem dúvida, o homem que os utiliza e fabrica, e é ele, em última instância, que se valendo deles atua sobre as matérias e as transforma de acordo com suas necessidades. O papel predominante dos meios de produção, acentuado por Marx, longe de eliminar a presença do homem concreto, como sujeito da produção, o revela inequivocamente. (p. 196)

Entretanto, essa "presença", sublinha Marx (1994), nunca acontece de maneira isolada, tendo como resultado que, no caso do capitalismo:

O produto deixa de ser o resultado imediato da atividade do produtor individual para tornar-se produto social, comum, de um trabalhador coletivo, isto é, de uma combinação de trabalhadores, podendo ser direta ou indireta a participação de cada um deles na manipulação do objeto sobre que incide o trabalho. [...] Para trabalhar produtivamente não é mais necessário executar uma tarefa de manipulação do objeto de trabalho; basta ser órgão do trabalhador coletivo, exercendo qualquer uma das suas funções fracionárias. A conceituação anterior de trabalho produtivo, derivada da natureza da produção material, continua válida para o trabalhador coletivo, considerado em conjunto. Mas não se aplica mais a cada um de seus membros, individualmente considerados. (p. 584)

A base do processo de produção social sempre é a relação entre o homem e a natureza (o que faz com que o trabalho das "mãos" e o trabalho do "pensamento" sejam dificilmente diferenciados). Marx concebe a dicotomia entre corpo e pensamento como fundada na divisão social do trabalho entre concepção e execução, dando, então, para o problema uma conotação histórica mais ampla e crítica. Markus (1982) coloca o diferencial das "dicotomias" que Marx apresenta, dizendo que elas "tornam possível precisamente essa ruptura da objetividade social imediatamente dada e presente, representando-a como o produto global das gerações precedentes, ao mesmo tempo objetivação humana e materialização social" (p. 98).

A principal crítica de Marx ao capitalismo é a forma como a exploração capitalista, ao inviabilizar a propriedade daqueles que produzem a riqueza com seu trabalho, aliena as capacidades humanas, entre elas as capacidades corporais: "o desenvolvimento geográfico desigual das práticas e sensibilidades corporais daqueles que vendem sua força de trabalho se torna uma das características definidoras da luta de classes travada tanto pelo capital como pelo trabalho" (Harvey, 2000, p. 150). Scarry (1985), sem esquecer o fato de a propriedade privada dos meios de objetivação das potencialidades humanas ser materializada na riqueza socialmente produzida pelo homem, constata a impossibilidade de haver em uma sociedade capitalista o livre desenvolvimento ou ampliação dessas capacidades. A questão da exploração e alienação corporal no trabalho capitalista ocorre não só pelas condições de trabalho, tais como a insalubridade, repetição extenuante de movimentos, jornadas de trabalho insuportáveis, mas no fato de que no capitalismo o trabalhador não tem como usufruir os objetos que produz. As condições de trabalho dentro da fábrica (impossíveis de serem desconsideradas) são, além disso, secundárias se comparadas com a totalidade do modo de produção que, por fim, acaba determinando diretamente as características das rotinas de trabalho citadas. Vasquez (1990) é incisivo nessa questão quando diz:

É assim que surge hoje todo um sistema de direção na empresa, que propugna "relações humanas" com respeito ao trabalhador. Ora, a passagem de uma práxis repetitiva a uma práxis autenticamente criadora não transita por essas "relações humanas" ditadas também pelo princípio de sujeição do homem ao principio da máxima 
rentabilidade, passando, isto sim, por uma transformação das condições materiais e sociais do próprio trabalho. (p. 274)

Da mesma forma, o trabalho também oferece as bases sobre as quais o relacionamento entre natureza e sociedade é efetivado, sendo nesse relacionamento construídas as capacidades humanas ligadas à corporeidade. Partindo do processo social e histórico de projeção, recebimento e transformação da sensibilidade e intelectualidade humana, baseado no processo coletivo de desenvolvimento de instrumentos que medeiam a relação homem e natureza, Scarry (1985) conclui que é o corpo e seus sentidos que diferenciam, individualizam e, ao mesmo tempo, socializam a experiência humana. Baseada na categoria trabalho, continua a autora:

[...] a socialização da percepção (sentience) deveria continuar a ser amplificada conforme avançamos para artefatos econômicos (dinheiro e capital) e políticos mais estendidos. Todo o trabalho de Marx é dedicado a sua crença de que isso não acontece. Se os lugares econômicos continuassem esse trabalho de amplificação, eles coletivamente constituiriam uma economia socialista, compatível com o aumento da "socialização da percepção (sentience)" que ocorrera nos espaços antecedentes; ao invés disso, a economia capitalista a reverte e enfatiza a "privacidade", contraindo ao invés de expandir o número de trabalhadores (makers) que serão descorporificados pelo seu próprio ato de criação, subvertendo o impulso e a intenção do que o imaginar era em suas origens. (p. 256)

Fazendo a mesma tentativa de Scarry (1985) em visualizar o trabalho no longo processo de criação social da corporeidade pelo trabalho, Woolfson (1982) apresenta uma gama considerável de pesquisas que sustentam a tese engelsiana de estar o trabalho na base da hominização do homem. Para a apreciação dessa consideração, há que se ter claro que as diferenças nos ritmos e nas características das transformações fazem com que essa relação seja dificilmente observada:
Uma "relação inversa" emerge entre a transformação da forma física da espécie humana e a modificação na forma de trabalho. Nos anteriores hominídios modificações insignificantes na técnica eram acompanhadas por substanciais modificações na morfologia. No Homo sapiens, maiores transformações na técnica e formas de atividade têm pequena importância para sua forma física. Os termos dessa "relação inversa" são estritamente materialistas, mas podem facilmente dar condições para uma visão idealista do cérebro como o fator primário do desenvolvimento, enquanto, como Engels afirma, "as mais modestas produções da mão trabalhadora foram recuadas como fundamento (background)". Foi precisamente nessas bases que Engels originalmente formulou seu ensaio sobre as origens humanas e criticou seus contemporâneos pelo seu idealismo.

(1982, p. 77)

Estudar o fenômeno produtivo desconsiderando o duplo aspecto da categoria trabalho ocasionou a limitação de conceber o desenvolvimento humano como fruto da idéia, do pensamento, do cérebro. Engels (1991) insurgiu-se contra isso. Ele mostrou que o conjunto das relações sociais capitalistas, que amarram a produção não com a satisfação das necessidades humanas, mas a submetem à necessidade de ampliação do capital, o processo produtivo no seu sentido amplo e também como atividade, aparece como concebido pelo pensamento e feito pela mão. $\mathrm{O}$ capital "apresenta-se", assim, como inteligência totalmente liberta das contingências da prática, sedimentada em longas cadeias históricas baseadas na repetição de gestos e procedimentos.

É a transformação da força de trabalho em mercadoria que aguça e explica o fato de o trabalho, visto como a relação entre homem e natureza, tornar-se um processo todo pensado antecipadamente pelo capitalista, dando a base concreta para a ampliação da divisão social entre trabalho manual e trabalho intelectual, para além e anteriormente a todo e qualquer processo de produção da existência.

Trata-se de considerar o grande trabalho histórico de especialização e transformação das forças produtivas, relações sociais e natureza, e enxergar que o 
problema não está no "coração do indivíduo", mas no inchaço do "corpo social" capitalista e na cisão entre concepção e execução impulsionada pela imperatividade de reprodução do capital, que acaba colocando a concepção como o momento privilegiado e desconectado da execução.

$O$ fato de o capital apresentar-se como inteligência é, assim, a inversão da concreta relação entre homem e natureza, necessariamente baseada na ação e na inteligência, embasamento este não percebido pela necessidade da produção e reprodução do capital que, entre outras coisas, explica pela mistificação o fato de aqueles que produzem a riqueza social não poderem usufruir dessa produção. Uma conseqüência desse processo é o fato de novas ciências estarem sendo vistas como mediadoras da construção de uma nova imagem do corpo, que, substituindo a antiga visão biológica e mecânica, não consegue, porém, romper os limites das relações sociais que a sustentam.

O que sustentamos, apoiados em Alves (2005), Vasquez (1990), Harvey (2000) e Scarry (1985) e na leitura que fazem de Marx (1994), é a impossibilidade do exercício e do reconhecimento da omnilateralidade humana no interior de relações sociais capitalistas, tanto fora quanto dentro das rotinas produtivas. Esse exercício e esse reconhecimento passam pela superação de tais relações.

\section{Conclusões}

Iniciamos as reflexões verificando que os estudos sobre o corpo, na atualidade, apresentam um status acadêmico marcado pela grande presença em várias áreas do conhecimento. Com o despontar das críticas aos "paradigmas da modernidade", a corporeidade acabou sendo considerada, pelos teóricos de inspiração pós-modernista, um dos únicos referenciais possíveis, em razão de seu caráter discursivo, localizado e informalizável.

Refutamos esse tipo de consideração sem esquecer, porém, que "uma crítica autêntica do pósmodernismo não podia ser uma recusa ideológica dele. Ao contrário, a tarefa dialética era abrir cami- nho através dele de forma tão completa que nosso entendimento da época emergisse transformado" (Anderson, 1999, p. 78). Nesse sentido, colocamos a possibilidade de exercer essa crítica tomando os processos formativos da corporeidade e evidenciando que eles podem ser analisados a partir das bases do materialismo histórico.

Essa intenção, para ser realizada e aprofundada também por futuros estudos, deve, em primeiro lugar, superar a resistência que a temática da corporeidade encontra em grupos de pesquisa em que o marxismo é a opção metodológica das análises. Um exemplo de crítica à resistência em relação ao estudo da corporeidade nos é dado por Konder (1998), quando, ao deter-se sobre algumas afirmações de Eagleton, questiona $\mathrm{o}$

\footnotetext{
[...] modo sardônico como Eagleton aborda a revalorização da corporeidade por autores pós-modernos. Há, sem dúvida, muito a se discutir sobre o assunto. Para que a discussão seja esclarecedora, porém, o caminho melhor não é o da desqualificação de uma posição pela outra. No entanto, Eagleton debocha do que chama de "saracoteios carnavalescos" do "discurso do corpo". E força um gracejo que aproxima a ginástica de Jane Fonda e a reflexão de Michel Foucault para descrever um movimento de degradação realizado a partir do abandono de Che Guevara! A frase é: "O socialismo de Guevara cedeu lugar à somatologia de Foucault e Fonda". (s.p.)
}

Acreditamos que essa resistência é compreensível e, em certos aspectos, preferível à aceitação irrefletida da relevância dos estudos sobre o corpo, que acontece baseada na idéia de que a corporeidade seria uma das saídas para enfrentar a "falência das grandes narrativas".

Apesar de reconhecermos que Eagleton possui uma forma irônica de criticar o "modismo" acadêmico em torno do corpo, assumimos como importantes suas reflexões sobre a corporeidade. Todavia e ao mesmo tempo, endossamos as análises de Konder, sobretudo ao afirmar que, no que tange à corporeidade, "há, sem dúvida, muito a se discutir sobre o as- 
sunto", da mesma maneira que "o caminho melhor não é o da desqualificação", mas sim o da pesquisa e de um questionamento fundamentado, detido e propositivo.

Um caminho possível para aproximar o referencial materialista histórico dos estudos da corporeidade é focalizá-la pelo trabalho. As questões da corporeidade e da sua formação, quando vistas pelas questões do trabalho, podem ter suas implicações aprofundadas, dando espaço para que sejam problematizados limites e contradições passíveis de ocorrer quando a corporeidade é analisada de forma afastada das correntes transformações nas formas de trabalho.

Com isso, essas considerações pretendem criar canais de diálogo entre os estudiosos das questões do corpo, da educação e os estudiosos do mundo do trabalho, embasados em Marx. Que, para aqueles, o mundo do trabalho deixe de significar distância, limitação, mera instrumentalização ou um mundo que não ofereça nem questões nem respostas. Aos estudiosos do trabalho e de Marx, que as questões da corporeidade, tanto no passado quanto hoje, sejam vistas como assuntos que extrapolam os problemas estéticos, localizados, consumistas e hedonistas; que também se configurem em um locus importante para entendermos as lutas que se estabelecem na sociedade em torno dos processos formativos.

\section{Referências bibliográficas}

ALVES, Giovanni. Trabalho, corpo e subjetividade: Toyotismo e formas de precariedade no capitalismo. Trabalho, educação $e$ saúde, v. 3, n. 2, p. 409-428, 2005.

ANDERSON, Perry. As origens da pós-modernidade. Rio de Janeiro: Jorge Zahar, 1999

ARENDT, Hanna. Condition de l'homme moderne. Paris: Pocket, 2005.

BAUDRILLARD, Jean. L'échange impossible. Paris: Galilée, 1999. La société de consommation. Saint Armand: Denoël, 2005.

BÖHLE, Fritz; MILKAU, Brigit. De la manivelle à l'écran: l'évolution de l'expérience sensible des ouvriers lors des changements technologiques. Paris: Eyrolles, 1998.
DALE, Karen. Anatomising embodiment and organization theory. London: Palgrave, 2001.

EAGLETON, Terry. A ideologia da estética. Rio de Janeiro: Jorge Zahar, 1993.

. As ilusões do pós-modernismo. Rio de Janeiro: Jorge Zahar, 1998.

ENGELS, Friedrich. A dialética da natureza. 5. ed. Rio de Janeiro: Paz e Terra, 1991.

FOSTER, Jhon Bellamy. Em defesa da história. In: WOOD, E.; FOSTER, J. (Orgs.). Em defesa da história: marxismo e pós-modernismo. Rio de Janeiro: Jorge Zahar Editora, 1999. p. 196-206. GIL, José. Metamorfoses do corpo. Lisboa: Relógio d'Água, 1997. HANCOCK, Philip; TYLER, Melissa. Working bodies. In: HANCOCK, Philip et al. (Orgs.). The body, culture and society: an introduction. Buckingham/Philadelphia: Open University Press, 2002. p. $84-100$.

HARVEY, David. O corpo como estratégia de acumulação. In: . Espaços de esperança. São Paulo: Loyola, 2000. p. 135160.

HETRICK, Willian; BOJE, David. Organization and the body: post-fordist dimensions. Journal of organizational change management, v. 5, n. 1, p. 48-57, 1992.

JAMESON, Fredric. Pós-modernismo: a lógica cultural do capitalismo tardio. São Paulo: Ática, 2002.

JUVIN, Hervé. L'avènement du corps. Paris: Gallimard, 2005.

KAPP, Ernst. Grundlinien einer Philosophie der Technik: Zur Entstehungsgeschichte der Kultur aus neuen Gesichtspunkten. Braunschweig: George Westermann, 1877.

KONDER, Leandro. O marxista belicoso. Teoria e debate, n. 39 , 1998. Disponível em: <http://www2.fpa.org.br/portal/modules/ news/article.php?storyid=2299>. Acesso em: 16 ago. 2006.

LE BRETON, David. La sociologie du corps. 5. ed. Paris: PUF, 2002. . Adeus ao corpo: antropologia e sociedade. São Pau-

lo: Papirus, 2003.

LEE, Lisa Yun. Dialectics of the body: corporeality in the works of Theodor W. Adorno. Dissertation (Doctorate of Philosophy) Duke University, Durhan, 1999.

LEINENBACH, Harald. Die Körperlichkeit der Technik: zur Organprojektionstheorie Ernst Kapps. Essen: Die Blaue Eule, 1990. LESSA, Sergio. Para além de Marx? Crítica da teoria do trabalho imaterial. São Paulo: Xamã, 2005.

LOWE, Donald. The body in the late capitalism USA. Durhan and London: Duke University Press, 1995. 
LUKÁCS, George. Ontologia do ser social: os princípios ontológicos fundamentais de Marx. São Paulo: Ciências Humanas, 1979. Ontología del ser social: el trabajo. Buenos Aires: Herramienta, 2004.

MARKUS, Gyorgy. Langage et production. Paris: Éditions Denoël Gonthier, 1982.

MARX, Karl. O capital: crítica da economia política, v. 1, livro 1. 14. ed. Rio de Janeiro: Bertrand Brasil, 1994.

MCNALLY, David. Bodies of meaning. Studies on language, labor and liberation. Albany: State University of New York Press, 2001.

MOOERS, Colin. Missing bodies: visibility and invisibility in the bourgeois public sphere. Disponível em: $<$ http://www.cpsa-acsp.ca/ paper-2003/mooers.pdf $>$. Acesso em 30 maio 2005.

NEGRI, Antonio; HARDT, Michel. Empire. Paris: Exils, 2000.

RABINBACH, Anson. The human motor: energy, fatigue and the origins of modernity. Los Angeles: University of California Press, 1992.

SCARRY, Elaine. The body in pain. The making and unmaking of the world. New York: Oxford University Press, 1985.

SELTZER, Mark. Bodies and machines. New York and London: Routledge, 1992.

SHILLING, Chris. The body in culture, technology and society. London: Sage, 2005.

SIBILIA, Paula. O homem pós-orgânico: corpo, subjetividade e tecnologias digitais. Rio de Janeiro: Relume Dumará, 2002.

VASQUEZ, Adolfo Sanchez. Filosofia da práxis. 4. ed. Rio de Janeiro: Paz e Terra, 1990.

VEBLEN, Thorstein. The theory of leisure class. 1899. Disponível em: <http://xroads.virginia.edu/ HYPER/VEBLEN/ veb_toc.html>. Acesso em: 4 ago. 2006.
VILLAÇA, Nízia; GÓES, Fred. Em nome do corpo. Rio de Janeiro: Rocco, 1998.

WOOLFSON, Charles. The labour theory of culture: a reexamination of Engels's theory of human origins. London, Boston and Henley: Routledge and Kegan Paul, 1982.

WOOD, Ellen Meiksins. O que é a agenda pós-moderna. In: WOOD, E.; FOSTER, J. (Orgs.). Em defesa da história: marxismo e pós-modernismo. Rio de Janeiro: Jorge Zahar, 1999. p. 7-22.

CARLOS HEROLD JUNIOR, doutor em educação pela Universidade Federal do Paraná (UFPR), é professor do Departamento de Pedagogia da Universidade do Centro-Oeste (UNICENTRO). Últimas publicações: “A educação física nas atas do congresso de instrução do Rio de Janeiro (1884)" (Revista Histedbr Online, n. 26, p. 114-129, jun. 2007); "Corporeidade e alteridade: reflexões a partir da história da educação e da área trabalho e educação" (Lecturas Educación Física e Deportes, v. 110, p. 1-12, jul. 2007); "Da instrução à educação do corpo: o caráter público da educação física e a luta pela modernização do Brasil no século XIX (1870-1925)" (Educar em Revista, n. 25, p. 237-255, jan./jun. 2005); em co-autoria com Luciane Neuvald, Margareth Maciel e Paulo Guilhermeti organizou Educação e alteridade (Guarapuava: Editora da UNICENTRO, 2007). Projetos de pesquisa em desenvolvimento: "Corpo, trabalho e educação no capitalismo tardio"; "Corpo e educação: análise histórica do pensamento educacional moderno"; e "Levantamento e catalogação de fontes primárias e secundárias para a história da educação em Guarapuava-PR”.E-mail: carlosherold@hotmail.com

Recebido em março de 2007 Aprovado em setembro de 2007 
Carlos Herold Junior

\section{Os processos formativos da} corporeidade e o marxismo: aproximações pela problemática do trabalho

O objetivo desse artigo é evidenciar a mútua importância que possuem os estudos sobre a formação da corporeidade e as reflexões baseadas no materialismo histórico. Para tanto, dividimos o texto em três momentos: no primeiro, analisamos a forma como a temática da corporeidade surge atrelada ao desenvolvimento dos paradigmas pós-modernistas de análise. No segundo, ao relacionarmos a análise do corpo com a análise do trabalho, mostramos a forma como a obra de Marx é aceita e criticada pelos analistas. $\mathrm{Na}$ terceira, desenvolvemos algumas possibilidades críticas de analisar a formação da corporeidade pelo materialismo histórico. Como resultado, podemos notar que, ao atrelar a análise do corpo às transformações no mundo do trabalho, podemos aprofundar as possibilidades das análises sobre o corpo na atualidade. Com isso, esperamos mostrar que a análise do corpo se constitui em uma importante temática para as reflexões sobre a sociedade capitalista, da mesma forma que a reflexão sobre as transformações na forma de trabalho dessa sociedade oferecem possibilidades valiosas aos estudiosos da corporeidade.

Palavras-chave: corporeidade; processos formativos; marxismo; materialismo histórico; trabalho; pósmodernismo

The formative processes of corporality and Marxism: approximations through the problematic of work

The aim of this article is to put in evidence the mutual relevance of the studies on corporal formation and the analysis based on historical materialism. For that, we divided the text in three moments: firstly, we analyse the way in which the issue of corporality arises related to postmodernist paradigms of analysis. In the second moment, when we relate the studies on body with those on labour, we show how Marx's works are accepted or criticised. We then, thirdly, develop some critical possibilities to study the corporal formation on the basis of historical materialism. As result, we could verify that by linking the issue of corporality with transformations in labour patterns it is possible to further analyses on the body. With that, we hope to prove that studies on the body are important themes for reflections on capitalist society, in the same way that reflections on the transformations in the form of labour offer valuable possibilities for researchers of corporality.

Key words: corporality; formative processes; Marxism; historical materialism; labour; post-modernism
Los procesos de formación de la corporeidad y el marxismo: aproximaciones por la problemática del trabajo

El objetivo de este artículo es evidenciar la mutua importancia que poseen los estudios sobre la formación de la corporeidad y las reflexiones basadas en el materialismo histórico. Por tanto, dividimos el texto en tres momentos: en el primero, analizamos la forma como la temática de la corporeidad surge con un vínculo fuerte unida al desenvolvimiento de los paradigmas pos modernistas de análisis. En el segundo, al relacionar el análisis del cuerpo con el análisis del trabajo, mostramos la forma como la obra de Marx es acepta y criticada por los analistas. En el tercero, desenvolvemos algunas posibilidades críticas de analizar la formación de la corporeidad por el materialismo histórico. Como resultado, podemos notar que, al unir con un vínculo fuerte el análisis del cuerpo a las transformaciones en el mundo del trabajo, podemos profundizar las posibilidades del análisis sobre el cuerpo en la actualidad. Con ello, esperamos mostrar que el análisis del cuerpo se constituye en una importante temática para las reflexiones sobre la sociedad capitalista, de la misma forma que la reflexión sobre las transformaciones en la forma de trabajo de esta sociedad ofrecen posibilidades valiosas a los estudiosos de la corporeidad.

Palabras claves: corporeidad; procesos de formación; marxismo; materialismo histórico; trabajo; pos modernismo 